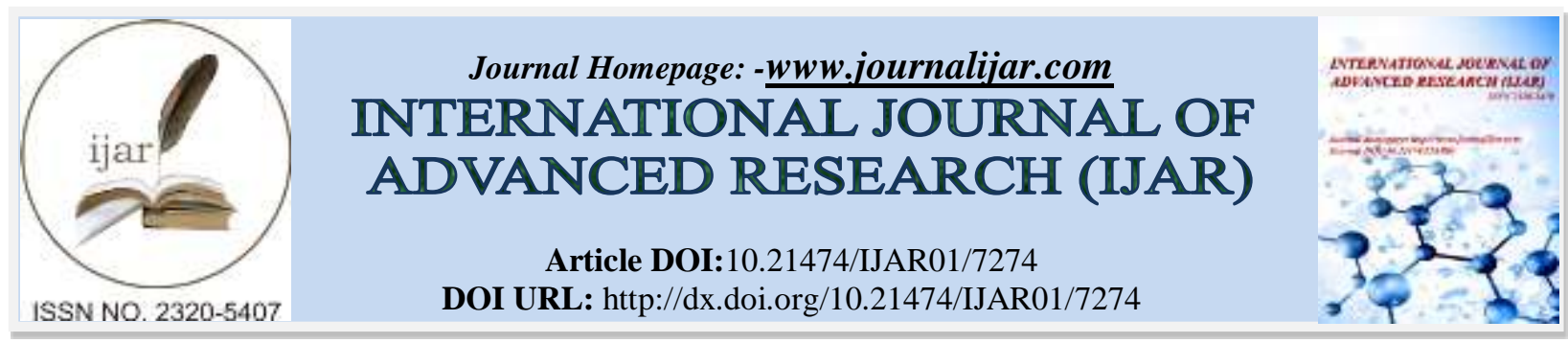

RESEARCH ARTICLE

\title{
DETERMINANTS OF ACCESS AND UTILIZATION OF MATERNAL HEALTH CARE AMONG DISPLACED PERSONS IN NORTH CENTRAL NIGERIA.
}

\begin{abstract}
Abolade Surajudeen Oladimeji (P.hd).
National Bureau of statistics, Department of Demography and Social Statistics, Abuja Nigeria.

\section{Manuscript Info}

Manuscript History

Received: 13 April 2018

Final Accepted: 15 May 2018

Published: June 2018

\section{Abstract}

This paper examined the influence of socio-demographic characteristics of displaced persons in flood affected States in Nigeria on their access and utilization of maternal health care services during displacement. A sample of 400 women who experienced displacement from their home during the 2012 flood disaster was purposively selected in Niger and Kogi State. The results showed that $98.0 \%$ of the displaced persons had health facilities close to their camp and most of these facilities were mainly Health Posts. The odds of a displaced person without education attending Antenatal clinic during displacement was $82.2 \%$ less than a displaced person with tertiary education while women with lower parity were less likely to attend antenatal clinic during their displacement. The study concluded that some background characteristics of the displaced persons had great influence on the use of maternal health care services during displacement which helped improve maternal health conditions in displaced setting.
\end{abstract}

Copy Right, IJAR, 2018, All rights reserved.

\section{Introduction}

Maternal morbidity and mortality is generally high in Sub-Saharan Africa and also in northern Nigeria in particular with the goals of safe motherhood eluding many governments. Maternal healthcare services are provided to pregnant women in order to monitor the progress of the pregnancy, delivery and to give mother and child proper antenatal and post-natal care. World Health Organization (WHO) estimated that 587,000 maternal deaths (World Health Organization, 2010) result each year from complications arising from pregnancy. Sub-Saharan Africa accounts for most of these deaths while Nigeria accounts for about $10 \%$ of all maternal deaths globally and has the second highest maternal mortality rate in the world after India (World Health Organization, 2004; Adam et al, 2005). These deaths are unjust and can be avoided with key health interventions, like provision of antenatal care and medically assisted delivery (Adam et al, 2005; MCcaw-Binns et al, 2007).

The recent sharp increase in the number of IDPs, up by 7.5 per cent at the end of 2011 was linked to worsening conflict and violence throughout Sub-Saharan Africa. About two-thirds of the world's forcibly uprooted people are displaced within their own country. According to Internal Displacement Monitoring Centre (IDMC), the global number of IDPs has steadily increased from a total of around 17 million in 1997 to 28.8 million in 2012. Women in displaced setting are at increased risk of maternal mortality because of absence of essential health facilities. Maternal health care in emergency situation is not a luxury, but a necessity that saves lives and reduces illness. Socio-demographic characteristics of women are strong influence on utilization of maternal health services among the people. In this regard, some good examples are maternal age and parity, education, poverty, place of delivery 
and residence (World Health Organization, 2007). Hence, this study focuses on the effect of the socio-economic and demographic characteristics of the displaced persons to overcome the barriers to access of maternal health services and its outcome on utilization of this essential health services among expecting mothers who are displaced.

\section{Statement Of The Problem:-}

High maternal morbidity and mortality rate is a huge public health problem in the developing countries of the world, including Nigeria. Despite the existence of national programs for improving maternal and child health in Nigeria, maternal mortality and morbidity continue to be high. In recent times, the Nigerian government has developed numerous policies and strategies that focus generally on health and, specifically, on maternal health. These policies recognize maternal mortality as a national problem and acknowledge the weaknesses of the health-care system in addressing women's health issues. The recent increase in the number of internally displaced persons due to conflicts, violence, natural disaster and developmental projects in Nigeria has made some of the Nigerian populace to be in deprived conditions in term of access to good and quality health care which exposed women who are pregnant to higher risk and the health strategies of the Nigerian government did not adequately capture the health needs of the displaced persons, hence this study seeks to know if government policies on health tend to cover people in the displaced situation.

Studies have shown that the majority of maternal deaths and disabilities can be prevented through early and timely access to and utilization of quality MHCS (Bhatia, 1993; Babalola \& Fatusi, 2009). However, many women in developing countries do not have access to MHCS and it is reported that the use of such services remain low in subSaharan Africa (Mekonnen \& Mekonnen, 2002; Mpembeni, 2007), including Nigeria (Galadanci et al, 2007; Babalola \& Fatusi, 2009); where only $58 \%$ of women have attended at least one antenatal clinic during pregnancy, $39 \%$ of births are attended to by a skilled professional, 35\% of deliveries take place in a health facility and $43.7 \%$ receive postnatal care (Nigeria Demographic Health Survey, 2008). These MHCS eludes most women in displaced setting because of many factors that serves has deterrent to their access to and utilizations of these important services. Previous studies have focus on community, individual and household factors associated with the use of maternal health services, however, studies have not sufficiently examined the displaced persons access to and utilization of maternal health services, hence this study.

\section{Objectives of the Paper}

The objective of the paper is to examine the contributions of socio-demographic characteristics of the internally displaced persons in explaining their access and utilization of maternal health care during displacement and also examine the level of responsiveness of Nigerian government to the provision of maternal health care services to people in displaced setting.

\section{Literature Review}

Displacement in Africa is complex. People are displaced for different reasons; conflict, natural disasters while some are evicted for urban renewal projects and still others are displaced because of large-scale development projects. Africa has more internally displaced persons (IDPs) than refugees; in fact, there are nearly five times as many IDPs. In 2010, there were around 2 million refugees in sub-Saharan Africa while the corresponding figure for IDPs was around 11 million (United Nations Office for the Coordination of Humanitarian Affairs, 2011). Africa is, and has long been, the region with the largest number of IDPs in the world. Out of an estimated 26.4 million IDPs in the world at the end of 2011, there were some 9.7 million IDPs in Sub-Saharan Africa, a figure which is down by 13 percent from 2010 when there were just over 11 million.

The World Health Organization constitution in 1948 defined the Right to Health as the right of all people "to the enjoyment of the highest attainable standard of physical and mental health". According to General Comment 14, the right to the highest attainable standard asserts the right to the highest possible level of health, which is a relative level dependent on individual biology, socio-economic conditions and available resources. However, the maternal health rights of women in the context of displacement are inadequately addressed in policy at the national level of many countries and the provisions applicable for the general population applies equally to IDPs. According to the 1998 United Nations Guiding Principles on Internal Displacement; it states that internally displaced persons shall enjoy, in full equality, the same rights and freedoms under international and domestic law as do other persons in their country. They shall not be discriminated against in the enjoyment of any rights and freedoms on the ground that they are internally displaced. These Principles shall be observed by all authorities, groups and persons, irrespective of their legal status, and applied without any adverse distinction. In particular, the Guiding Principles 
states explicitly that special attention should be given to the health needs of women, including access to quality health care services, such as maternal health care.

An assessment carried out in Southern and East African countries on progress made towards the Abuja target, Govender et al (2008) observed that among countries reviewed, only Zambia and Malawi have made considerable progress towards the target, with the health sector's share of total government expenditure increasing consistently from $8 \%$ and 5\%, respectively, in 1997 to nearly $11 \%$ and $7 \%$ in 2000 and almost $18 \%$ and $11 \%$ in 2003 (thus, Zambia exceeding the Abuja target).

Different factors prevent women from utilizing skilled services, for example, in a study carried out in the Ahafo-Ano South district, Ghana, it was revealed that inaccessible roads to health facilities and the lack of access to vehicles account for the low utilization of skilled attendants (Nai- Adjei, 2008). According to UNFPA (2004), difficult geographic terrain and limited transportation may present obstacles to reaching a skilled attendant. Tsanga (2011) suggested that the main challenges for poor rural women in accessing health care include transportation difficulties, poverty and lack of access to health care information. A study in Nepal shows that living far away from a health facility is eight times more likely to lead to non-use of the health facility for delivery (Wagle et al, 2004). Claeson, et al (2001) agrees that if proximity to health services are not easily accessible, then the issue of whether they are properly staffed or not is irrelevant.

The study carried out in Ahafo -Ano South district, Ghana, showed that cost can be an important obstacle to the decision to seek lifesaving care in many settings. For most women, cost was a major barrier to obtaining appropriate medical care; those delivering in a public facility had to pay medical fees, anesthetic and antibiotic costs and the cost of surgical supplies, such as gloves and surgical drapes (Nai Adjei, 2008). Mrisho et al (2007) assert that women still deliver at home despite the availability of maternity services and cite fees and low income as reasons for not using the health facility in Nigeria. Further, the reproductive health needs of women are exacerbated by the likelihood that the health services are extremely limited or essentially unavailable. Consequently, complications of pregnancy and child birth are not addressed appropriately. It is estimated that about $15 \%$ of pregnant women in emergency situations experience complications during pregnancy or delivery that are life-threatening and require emergency obstetric care (World Health Organization, 2005). When such care is not available, the likelihood of maternal death increases.

In Nigeria, according to the 2008 Nigerian Demographic Health Survey (NDHS), Nigeria's maternal mortality ratio (MMR) is high, at 545 maternal deaths per 100, 000 live births, well above the 2015 MDG target of 147 per 100, 000. Although, vast majority (58\%) of women were reported to have received some antenatal care (ANC) from a skilled provider, among these women $45 \%$ had visited antenatal clinics at least four times during pregnancy, and $8 \%$ reported two or three antenatal visits while $2 \% \mathrm{t}$ of the women had just one antenatal care visit, 36 percent did not receive any antenatal care visit (NDHS, 2008). More than half of Nigeria's births occur at home. $35 \%$ of births in Nigeria are delivered in a health facility; $20 \%$ deliveries occur in public sector facilities and $15 \%$ in private facilities. Three out of five births (62\%) occur at home. The most commonly given reasons for not going to a health facility to give birth were cost, distance and a lack of transportation (NPC \& ICF Macro, 2009).

In terms of safe motherhood, the 2001 assessment of reproductive health services of IDPs in Angola painted a very bleak picture (Meriwether et al, 2001). Antenatal care was available at only some health posts and health centres, although it was noted that few women accessed antenatal care, possibly because women level of awareness of the importance of antenatal care or that services were not widely available and accessible to them. Majority of women were said to deliver at home with a TBA in attendance; 'home' for an IDP was described as a tent shared with another family or a straw hut with a dirt floor. Some deliveries took place under a tree, in a classroom or in some other structure within the camp. Additionally, the hospitals had very poor sanitary conditions and were poorly equipped and staffed, leading to high rates of life-threatening postpartum infections, among other complications (Meriwether et al, 2001).

Krause (2003) in his assessment carried out in Colombia, showed the reproductive health needs of IDPs rather than assessing existing services. Nonetheless, in terms of safe motherhood services, the report indicated that IDP women received less antenatal care than did Colombian women as a whole. In addition, because of their inability to pay for services, IDP women who needed EmOC were referred from one hospital to another, delaying the provision of lifesaving care. (Krause, 2003). 
Hynes et al (2002) study of reproductive health indicators and outcomes among refugees and IDPs living in 52 postemergency phase camps in seven countries (Azerbaijan, Ethiopia, Myanmar, Nepal, Tanzania, Thailand, and Uganda) was that refugees and IDPs in most post-emergency phase camps had better reproductive health outcomes than people in their respective host country and country-of-origin populations.

A number of socio-demographic characteristics of the individual affect the underlying tendency to seek care (Addai, 2000). In this regard, good examples are maternal age and parity, which have been examined as determinants of health care use repeatedly (Adekunle et al, 1990; Celik and Hotchkiss, 2000; Leslie and Gupta, 1989). The greater confidence and experience of the older and higher parity women, together with greater responsibilities within the household and for child care, have been suggested as explanatory factors for their tendency to use services less frequently (Kwast and Liff, 1988). Maternal education has also been shown repeatedly to be positively associated with the utilization of maternity care services (Addai, 2000; Addai, 1998; Akin and Munevver, 1996; Beker et al, 1993; Celik and Hotchkiss, 2000; Ferdnandez, 1984; Stewart and Sommerfelt, 1991).

Another important factor in the utilization of maternal care services, especially in Africa, is the cultural background of the woman (Leslie and Gupta, 1989; Pelto, 1987). The cultural perspective on the use of maternal health services suggests that medical need is determined not only by the presence of physical disease but also by cultural perception of illness (Addai, 2000). In most African rural communities, maternal health services coexist with indigenous health care services; therefore, women must choose between the options (Addai, 2000). The use of modern health services in such a context is often influenced by individual perceptions of the efficacy of modern health services and the religious beliefs of individual women (Adetunji, 1991). Moreover, in many parts of Africa, women's decisionmaking power is extremely limited, particularly in matters of reproduction and sexuality (World Health Organization, 1998).

\section{Methodology:-}

The study used primary data. Two States that were affected by 2012 flood in North Central (Niger and Kogi State) were used for the study; the rationale for the selection is that these States were most affected by the 2012 flood in the North-Central zone. Local Government Area that were greatly affected by the flood in the selected States was used for the study; Wushishi and Shirroro Local Government Areas (LGAs) in Niger State and Lokoja and Ajaokuta(LGAs) in Kogi State. Since the study is on maternal health care utilization, the target groups are women aged 15-49 years old that experienced displacement from their homes during the 2012 flood disaster in the selected LGAs. The National Population Commission Enumeration Area (EA) of the selected LGAs was used to generate the frame for the study. Five EAs were randomly selected and used in each LGA. From each of the selected EA, 20 respondents that were affected by the flood were purposively selected and interviewed. A total of one hundred respondents were interviewed from each LGA. In total, 400 respondents were purposively selected and interviewed from the two states. One Focus Group Discussion (FGD) was conducted in each of the selected LGAs in order to collect additional information on experiences as regards maternal health services during the displacement. Each FGD had at least eight persons to participate in the discussion. The target populations in this study are all the women aged 15-49 in communities that were affected by the 2012 flood and were displaced from their usual place of residence for some time before their return.

\section{Data Analysis:-}

In order to examine all aspects of data collected, quantitative and qualitative methods of data analysis were used. The descriptive analysis employed the use of frequency distribution table for all the variables considered during displacement. The bivariate analysis revealed the pattern of association between some background characteristics of the displaced persons (e.g age of mother, parity and religion) were cross tabulated against utilization of maternal health like Antenatal care clinic attendance and use of trained medical personnel for delivery.

Binary logistic regression analysis was used to assess the relationship between the independent variables and the dependent variable. Logistic regression analysis is used because of its similarity to linear regression model and due to the dichotomized nature of the dependent variable. Controlling for some factors at different stages, a nested model logistic regression analysis was applied in examining the net effects of some statistically significant independent variables on the dependent variable. Utilization of maternal health services among the displaced persons is the outcome variable in this study and as stated earlier; it is measured in four ways. Therefore, to be able to see the nested effect of all the independent variables on utilization of maternal health services among the displaced persons, 
the application of the proposed logistic regression model was performed. Reference category (RC) takes on the value of one (1.000) and any value less than one implies that displaced persons in that category have a lower probability of utilizing maternal health services.

\section{Availability and Type of Health Facilities in the Camp/Host Communities}

The availability of health facilities in communities where the displaced persons were camped is an essential factor to encourage utilization of health care services. The distribution of respondents as shown in Table 1 indicates that most of the respondents $(98.0 \%)$ had health facilities close to where they were camped. As shown in Fig.1, the types of health facilities available in the camp were mostly Health Post $(60.0 \%$

\begin{tabular}{|c|r|r|}
\hline & Frequency & \multicolumn{2}{|c|}{ Percentages } \\
\hline Yes & 392 & 98.0 \\
\hline No & 8 & 2.0 \\
\hline Total & 400 & 100.0 \\
\hline
\end{tabular}

Source: Survey report, 2011

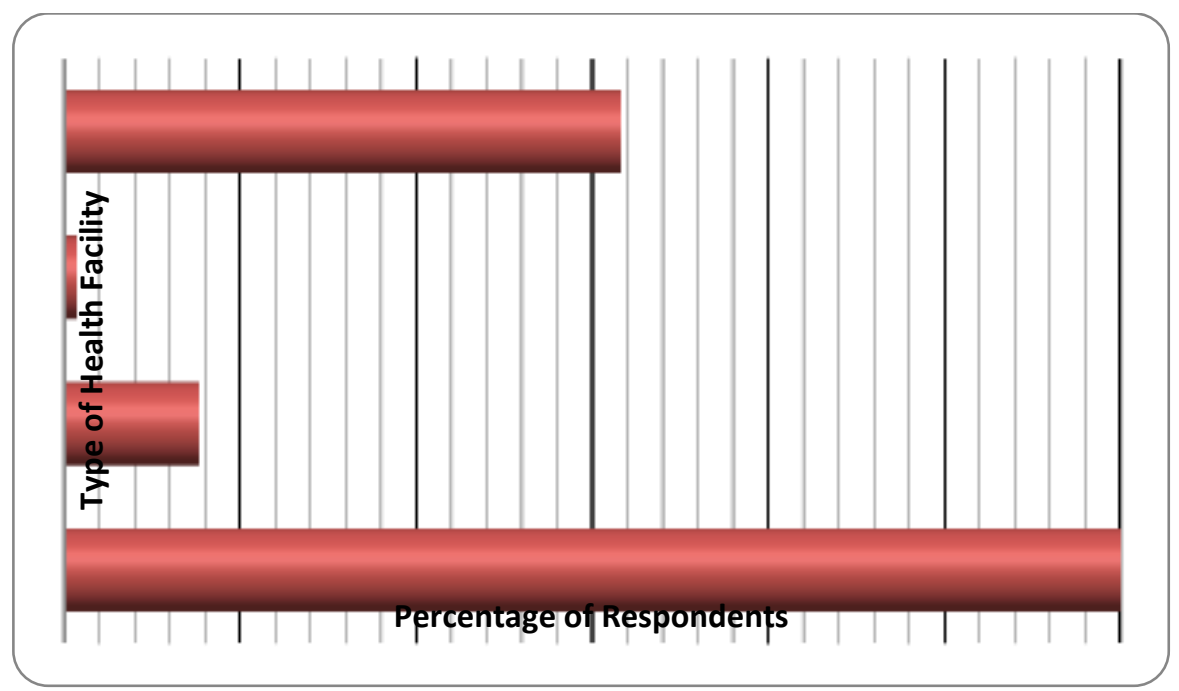

Fig 1: Percentage distribution of respondents on Type of Health Facility available in Camp

\section{Distance of Health Facilities from the Camp/Host Communities}

Proximity of the health facilities to the displaced person's camp can be a source of encouragement in their use of maternal health service. As depicted in Fig.2, more than half of the respondents (53.7\%) claimed that the health facilities are located at a close distance of less than $1 \mathrm{~km}$ from the camp while $30.3 \%$ reported that the health facilities were within the range of $1-2 \mathrm{~km}$ from the camp; the remaining $16.0 \%$ said that the health facilities is far from the camp (more than $3 \mathrm{~km}$ ). 


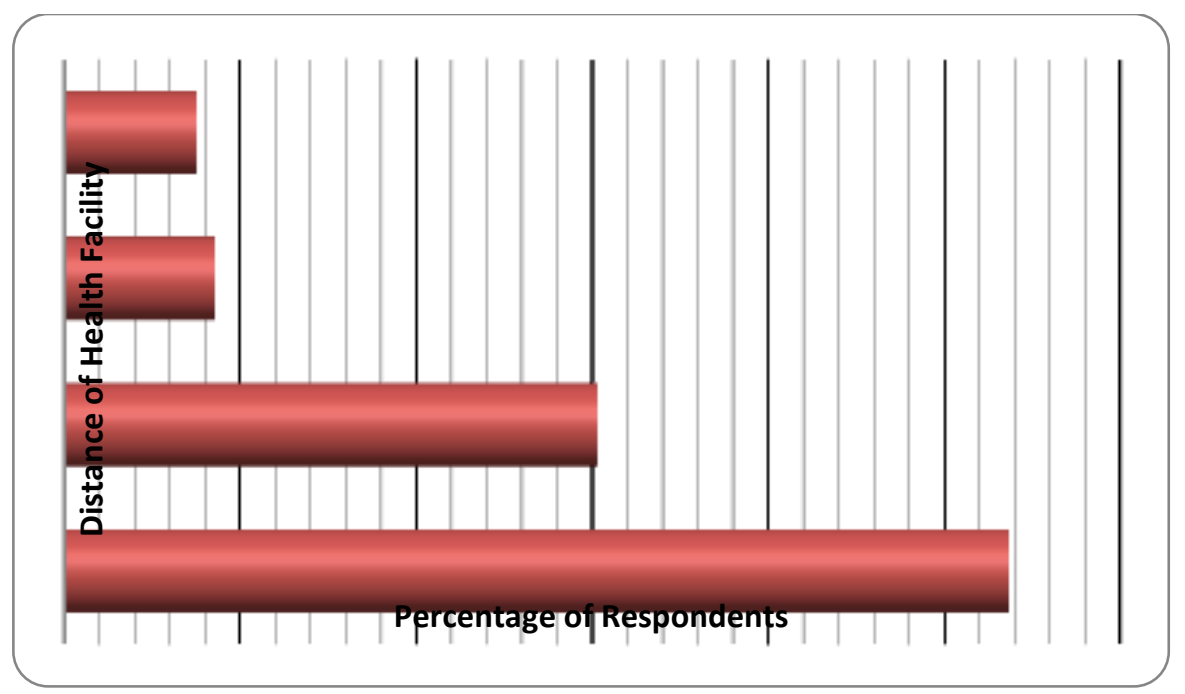

Fig 2: Percentage distribution of respondents on Distance of Health Facility from the Camps

\section{Utilization of Maternal Health Services}

The indicators that were used to measure the extent of utilization of maternal health services in this paper are antenatal clinic attendance and use of trained medical personnel during delivery. The distribution of respondents as presented in Table 2 shows that most of the women (87.5\%) attended antenatal care clinic during pregnancy during their displacement although most of the women (68.0\%) started ANC during the second trimester of their pregnancy while some started in third trimester $(20.8 \%)$. The Nurse/Midwife mostly assisted the women during delivery because most of the available health facilities to the camps of the displaced persons were mainly health post and is managed mainly by nurses or midwife. Majority of the women had a normal delivery (98.7\%).

Table 2: Percentage distribution of respondents by Utilization of Maternal Health Services Source: Survey report, 2014

\begin{tabular}{|l|r|r|}
\hline Characteristics & Frequency $\mathbf{( n = 4 0 0 )}$ & Percentages \\
\hline Had Antenatal & & \\
Yes & 350 & 87.5 \\
Wo & 50 & 12.5 \\
Yes & & \\
No & 31 & 7.8 \\
Nurse/Midwife & 369 & 92.2 \\
Yes & & \\
No & 278 & 69.5 \\
Traditional Birth Attendant & 122 & 30.5 \\
Yes & & \\
No & 2 & 0.5 \\
Community Health worker & 398 & 99.5 \\
Yes & & \\
No & 79 & 19.8 \\
When ANC started & 321 & 80.3 \\
First trimester & & \\
Second trimester & 45 & 11.3 \\
Third trimester & 272 & 68.0 \\
Number of ANC visits during pregnancy & 83 & 20.8 \\
1-3 & & 27.0 \\
$4-6$ & 108 & 38.7 \\
$7+$ & 155 & 34.3 \\
\hline
\end{tabular}




\begin{tabular}{|l|r|r|}
\hline Who assisted during delivery & & 42 \\
Doctor & 282 & 10.5 \\
Nurse/Midwife & 42 & 70.5 \\
Community Health Attendant & 4 & 10.5 \\
Traditional Birth Attendant & 30 & 1.0 \\
Friend/Relative & & 7.5 \\
Were you delivered by Caesarean Section? & 5 & 1.3 \\
Yes & 395 & 98.7 \\
No & \\
\hline
\end{tabular}

Influence of Respondent's Background Characteristics on selected Indicators of Barrier to Utilization of Maternal Health Services

A number of socio-demographic characteristics of individual influence the underlying tendency to seek care (Addai, 2000). However, accessing this care in a displaced circumstance may be hindered by distance of hospitals, cost of services and attitude of the medical personnel. The relationship between the background characteristics of the respondents and its influence to overcome some challenges to the use of maternal health services among the displaced persons cannot be overemphasized.

Table 3: Relationships between selected Background Characteristics of Respondents and Assisted by Trained Medical Personnel during Delivery

\begin{tabular}{|c|c|c|c|c|c|}
\hline & \multicolumn{3}{|c|}{ Assisted by Trained Medical Personnel } & \multirow[t]{2}{*}{ Chi Square } & \multirow[t]{2}{*}{ P-Value } \\
\hline & Trained Person & $\begin{array}{l}\text { Untrained } \\
\text { Person }\end{array}$ & Total & & \\
\hline $\begin{array}{l}\text { Educational } \\
\text { Attainment } \\
\text { None } \\
\text { Primary } \\
\text { Secondary } \\
\text { Tertiary } \\
\text { Total }\end{array}$ & $\begin{array}{l}63(90.0) \\
140(92.7) \\
44(93.6) \\
77(58.3) \\
324(81.0)\end{array}$ & $\begin{array}{l}7(10.0) \\
11(7.3) \\
3(6.4) \\
55(41.7) \\
76(19.0)\end{array}$ & $\begin{array}{r}70(100.0) \\
151(100.0) \\
47(100.0) \\
132(100.0) \\
400(100.0) \\
\end{array}$ & 66.08 & 0.00 \\
\hline $\begin{array}{l}\text { Religion } \\
\text { Christianity } \\
\text { Islam } \\
\text { Others } \\
\text { Total }\end{array}$ & $\begin{array}{r}90(95.7) \\
234(77.0) \\
0(0.0) \\
324(81.0)\end{array}$ & $\begin{array}{r}4(4.3) \\
70(23.0) \\
2(100.0) \\
76(19.0)\end{array}$ & $\begin{array}{r}94(100.0) \\
304(100.0) \\
2(100.0) \\
400(100.0)\end{array}$ & 25.00 & 0.00 \\
\hline
\end{tabular}

Education has been shown to be one of the factors that influence a person's desire to seek quality health care (Adamu, 2011). Table 3 indicates that $81.0 \%$ of the respondents were assisted by trained medical personnel during delivery of their babies. It was discovered that among respondents with primary, secondary and tertiary education, $92.7 \%, 93.6 \%$ and $58.3 \%$ respectively used trained medical personnel for delivery of their babies. The finding further shows that education has a great influence on the behavior of the displaced persons in connection to the use of trained medical personnel for delivery (Chi-Square $=66.08 ; \mathrm{df}=3 ; \mathrm{p}<0.05$ ). Also, most of the respondents with no formal education made use of trained medical personnel $(90.0 \%)$ for the delivery of their babies even though they have never attended formal school. This is possible because they might have received enlightenment on the importance of using trained medical personnel from their relatives, friends or neighbor which is also a form of education which would have informed their decision to use the trained personnel during delivery.

Table 3 further showed that among the Christian (95.7\%) were assisted by trained medical personnel during the delivery of their babies while among the Muslims faithful (77.0\%) used the services of trained medical personnel for the delivery of babies. Religion is shown to have influence on the attitude of his members in seeking health care services $($ Chi-Square $=25.00 ; \mathrm{df}=2 ; \mathrm{p}<0.05)$. it implies that religion is significant to the use of trained medical personnel by the displaced persons during delivery of their babies because the sermon heard from the religious leaders goes a long way to influence the decision of type of health care service that will be seek by members of the religious group. 


\section{Multivariate Analysis}

Table $4 \& 5$ presents odds ratio estimates from logistic regression analysis models on the use of maternal health care services among displaced women by selected background characteristics. The multivariate analyses help to predict the outcome of the dependent variable based on the values of a set of predictors (independent variables) running simultaneously in a single model. Utilization of maternal health services is the outcome or dependent variable in this study and it is measured in four ways; (1) antenatal clinic attendance (2) assisted by trained medical personnel during delivery while the set of independent variables considered in this study includes age, education, children ever born and religion. Therefore, to be able to see the nested effect of all the independent variables of the displaced persons on utilization of the maternal health services, the regression model was performed. As presented in Table 4, it shows the relative effects of selected background characteristics of the displaced persons on Antenatal clinic attendance. The result shows that the odds ratio of a displaced person without education attending Antenatal clinic during displacement is (82.2\%) less likely to attend Antenatal clinic than a displaced person with tertiary education while among the displaced persons with secondary education the odds ratio of antenatal clinic attendance during displacement is $(16.2 \%)$ less than a displaced person with tertiary education. The table further shows that displaced persons who are not Christians are less likely to attend Antenatal clinic than the Christians. The table reveals that the odds ratio of antenatal clinic attendance of a Muslim faithful in the displaced camp is $94.8 \%$ less than a displaced person who is a Christian. The result is not statistically significant which implies that religion of a displaced person is not the major predictor of antenatal clinic attendance.

The number of children ever born by the displaced persons is also not statistically significant to Antenatal clinic attendance as depicted in Table 4, the result shows that respondents with lower parity are less likely to attend antenatal clinic during their displacement. The odds ratio of a displaced person with (1-3) children to attend antenatal clinic is $25.1 \%$ less than a displaced person with more than three children. This implies that those with more children have experience and have seen needs to attend antenatal clinic during pregnancy than those without children. Finally, the age of the displaced persons was considered to know the effect age of the displaced persons on Antenatal clinic attendance, the result indicates that displaced woman who is between the age range 15-24 years is $35.3 \%$ less likely to attend antenatal clinic than a displaced woman that is over 45 years, although the result is not statistically significant to Antenatal clinic attendance.

Table 4:- Odds Ratios (Logistic Regression Models) of Antenatal Clinic Visits and Socio-economic Variables of Respondents.

\begin{tabular}{|c|c|c|c|c|c|}
\hline \multirow[t]{2}{*}{ Variables } & \multicolumn{3}{|c|}{ ANTENATAL VISITS } & \multicolumn{2}{|c|}{ 95\% Confidence Interval } \\
\hline & B. Coefficient & Odd ratio & Significant & Lower & Upper \\
\hline Educational & & & & & \\
\hline No Education & -1.725 & 0.178 & & 0.035 & 0.910 \\
\hline Primary & -0.302 & 0.740 & 0.215 & 0.345 & 1.586 \\
\hline Secondary & -0.176 & 0.838 & & 0.183 & 3.850 \\
\hline Tertiary & $\mathrm{RC}$ & 1.000 & & & \\
\hline Religion & & & & & \\
\hline Islam & -2.948 & 0.052 & & 0.001 & 2.384 \\
\hline Others & -2.015 & 0.133 & 0.138 & 0.003 & 5.130 \\
\hline Christianity & $\mathrm{RC}$ & 1.000 & & & \\
\hline Children Ever Born & & & & & \\
\hline No Child & -0.130 & 0.878 & & 0.168 & 4.576 \\
\hline $1-3$ & -0.289 & 0.749 & 0.375 & 0.202 & 2.779 \\
\hline $4-6$ & -0.906 & 0.404 & & 0.122 & 1.341 \\
\hline $7+$ & $\mathrm{RC}$ & 1.000 & & & \\
\hline Age Group & & & & & \\
\hline $15-24$ & -0.435 & 0.647 & & 0.085 & 4.902 \\
\hline $25-34$ & -0.439 & 0.645 & 0.617 & 0.109 & 3.808 \\
\hline $35-44$ & -1.032 & 0.356 & & 0.063 & 2.000 \\
\hline Over 45 & $\mathrm{RC}$ & 1.000 & & & \\
\hline
\end{tabular}


As depicted in Table 5, the displaced persons' religion and age were not significantly related to the use of trained medical personnel during the delivery of their babies. Similarly, the table shows that the odds ratio of a displaced persons that were younger in age are more likely to use the services of trained medical personnel during the delivery than those who were over 45 years; it is revealed that displaced persons whose ages are 15-24 years are more than six times more likely to use the services of trained medical personnel during delivery than displaced persons whose ages are over 45 years. For those whose ages were 25-34 years were more than twice more likely to use trained personnel during delivery than displaced women of over 45 years. The religion of the displaced person shows that displaced women who were Muslims are less likely to use trained medical personnel during delivery of their babies than the Christians women. The table also indicates that education and children ever born of the displaced persons were significantly related to their use of trained medical personnel during the delivery of their babies. The table shows that displaced persons with lower level of educational attainments were less likely to use trained medical personnel during delivery of their babies than those with tertiary education; it is revealed that displaced person with no formal education is $60.8 \%$ less likely to use trained medical personnel for delivery than a displaced person with tertiary education while those with secondary education is $50.6 \%$ less likely to use the services of trained medical personnel for delivery than those with tertiary education. The displaced women with low parity were less likely to use trained medical personnel during the delivery of their babies than those with more than seven children; it is revealed that the odds ratio of a displaced person with (1-3) children to use trained medical personnel for delivery is $85.1 \%$ less than a displaced person with more than three children.

Table 5:- Odds Ratios (Logistic Regression Models) of Assisted by Trained Medical Personnel during Delivery and Socio-economic Variables of Respondents.

\begin{tabular}{|c|c|c|c|c|c|}
\hline \multirow[t]{2}{*}{ Variables } & \multicolumn{3}{|c|}{ TRAINED MEDICAL PERSONNEL } & \multicolumn{2}{|c|}{ 95\% Confidence Interval } \\
\hline & B Coefficient & Odd ratio & Significance & Lower & Upper \\
\hline Educational & & & & & \\
\hline Attainment & & & 0.000 & 0.150 & 1.010 \\
\hline No Education & -0.935 & 0.392 & & 0.081 & 0.426 \\
\hline Primary & -1.712 & 0.181 & & 0.121 & 2.080 \\
\hline Secondary & -0.705 & 0.494 & & & \\
\hline Tertiary & $\mathrm{RC}$ & 1.000 & & & \\
\hline Religion & & & 0.237 & 0.000 & 0.924 \\
\hline Islam & -24.091 & 0.000 & & 0.000 & 0.830 \\
\hline Others & -23.088 & 0.000 & & & \\
\hline Christianity & $\mathrm{RC}$ & 1.000 & & & \\
\hline Children Ever Born & & & & & \\
\hline No Child & -2.724 & 0.066 & 0.011 & 0.012 & 0.389 \\
\hline $1-3$ & -1.903 & 0.149 & & 0.041 & 0.521 \\
\hline $4-6$ & -1.387 & 0.250 & & 0.085 & 0.783 \\
\hline $7+$ & $\mathrm{RC}$ & 1.000 & & & \\
\hline Age Group & & & & & \\
\hline $15-24$ & 1.899 & 6.676 & & 0.847 & 52.683 \\
\hline $25-34$ & 1.055 & 2.871 & 0.149 & 0.472 & 17.430 \\
\hline $35-44$ & 0.326 & 1.385 & & 0.254 & 7.513 \\
\hline Over 45 & $\mathrm{RC}$ & 1.000 & & & \\
\hline
\end{tabular}




\section{Discussion of Findings}

The main research question is to examine the effect of socio demographic characteristics of displaced persons on is access and utilization of maternal health care services. Hence, an insight to the personality and composition of the selected respondents help to give a better explanation to the findings. The age of the respondents as indicated in the survey showed that bulk of the respondents were between 25-34 years with a mean age of 31 years. This indicates that majority of the women are mature and by implication will have a better experience in child-birth. The dangers attached to pregnancy are issues they are aware of, either from personal experience or from families and friends. The educational status of the respondents shows that $66.3 \%$ attended school; this indicates that more than half of the respondents can read and write which could assist them in information gathering either from the print media or television. According to World Health Organization (2005), all pregnant women need to have access to skilled care throughout pregnancy, delivery, postpartum and postnatal periods. Considering availability and type of health facilities available in the camp, it is revealed that most of the respondents $(98.0 \%)$ had health facilities where they were camped and these facilities were mostly Health Post (60.0\%), also most of these health facilities are less than $1 \mathrm{~km}$ from the camp and they rendered maternal health services to the displaced persons which includes Antenatal care, postnatal care and Immunizations. The 1998 United Nations Guiding Principles on Internal Displacement states explicitly that special attention should be given to the health needs of women, including access to quality health care services, such as maternal health care. This finding shows that government considered health issues of the displaced persons before they chose the location the displaced camp is to be sited but the study further indicates that the quality of care that the internally displaced persons have access to is not comprehensive enough to meet up with the needs of the expecting mothers since most of the camp only have access to Health post. Closeness of the health facility for easy access encourage the IDPs to make good use of the health facilities and in situation where there is no health facility close to the camp, government employed some trained medical personnel for the camp and provide drugs and equipment for use. By implication, the IDPs are limited in their choice of use of health facility. World Health Organization (2005) stated that up to $15 \%$ of all births are complicated by a potentially fatal condition. These complications are unpredictable but can be prevented depending on the level of use of available maternal health services. The study revealed that most of the women $(87.5 \%)$ attended antenatal care clinic during pregnancy. Furthermore, more than half of the women delivered their babies in government hospitals $(64.0 \%)$ and the finding revealed that the sampled women $(91.0 \%)$ acknowledge that cost of services is not a barrier to their access of maternal health services during the displacement because the costs of services were moderate. These findings show that to an extent the government has made the issue of maternal health care for pregnant women to be affordable for the displaced persons and in most cases, the health strategies in most of the State in Nigeria is free at the primary care level, that is most of the services in the Health Post are free including maternal health services. By implication the study shows that awareness on the use of maternal health services among the displaced person is considerably high but more still need to be done to increase sensitization for some women that still believed in home delivery of pregnancy and also who do not attend Antenatal clinic because of the notion that they are strong and do not need any medical check-up for the unborn child and themselves.

Several studies found out that women's age plays a significant role in the utilization of maternal health care. It is indicated in the study that women whose age were more than 25 years had more antenatal clinic attendance than those who were less than 25 years possibly because women in these age brackets are more exposed to information from the media which includes enlightenment programme about the importance of ANC attendance for pregnant women. Moreover, over the years women with older age would have seen the importance of ANC in preventing any complication during pregnancy either from personal experience or from family, friends or possibly neighbors. The implication of this finding is that more sensitization still need to be done among young women who are pregnant to make good use of the health facilities, even if it is unwanted pregnancy, they need to think about the girl's health and her future before any other thing.

Religion is a powerful influence on the attitude of people. It is revealed in the study that Christians use maternal health care services more than the Muslim faithful. This implies that more sensitization still needs to be done through the Muslim religious leaders on the importance of maternal health care for the pregnant women in their congregation. The study revealed that all the socio-economic variables of the respondents considered were significantly related with the use of trained medical personnel for delivery. The result is similar with other results which revealed that education has a positive relationship with maternal health care utilization since educated mothers are considered to have a greater awareness of the existence of maternal health care services and benefits in using such services. This finding implies that individual background characteristics of the displaced persons help shape their behavior towards the use of maternal health services during displacement and these qualities includes 
education, religion and number of children ever born. It can be deduced that the socio-economic characteristics of the displaced persons have a serious influence on their behavior on the level of utilization of maternal health services available in the camp. Government need to do more to encourage female education and also female empowerment through provision of soft loan for the women to be engaged in any form of economic activities that can provide them with consistence income so that in situation where the family head might not want to support in the use of the maternal health services available, the women can be able to provide for themselves.

\section{Conclusion and Policy Recommendations:-}

The study concluded that the behavior of the displaced persons towards the use of maternal health care services during displacement can be linked to some of the socio demographic characteristics of the displaced person, although, independent effects of socio-demographic factors of the displaced persons may not provide enough explanations for the use of maternal health care during displacement.

The evidence from this study suggests that public health policies aimed at reducing maternal morbidities and mortalities in Nigeria should include strategies that will improve MHCS among women in displaced setting through: Increasing maternal education among mothers generally.

Provision of well-equipped and well staff health care centre either in the camp or very close to the camp of the displaced persons.

Campaigns against social norms that are harmful to women's health such as early marriage and a woman should have the right to choose the kind of medical services she want, not the family members taking the decision on her behalf.

Cost of services for pregnant women should be highly subsidized for everyone to help encourage the women to attend antenatal during pregnancy and also cost of delivery in the health facility needs to be subsidized especially for people in displaced setting.

Education programmes to women of Islamic and traditional beliefs on the importance of MHCS utilization are very paramount in the northern region of Nigeria. These programmes can be routed through religious leaders or traditional/community leaders. 


\section{References:-}

1. Adamu, Y.M. \& Salihu, H.M. (2002). Barriers to the use of antenatal and obstetric care services in rural Kano, Nigeria. Journal on Obstet Gynaecol. 2002; 22 (6): 600-603

2. Addai, I. (2000). Determinants of use of maternal-child health services in rural Ghana. Journal of Biosocial Science 32(1): 1-15.

3. Adekunle, C., Filippi, V., Graham, W., Onyemunwa, P. \& Udjo, E. (1990). Patterns of maternity care among women in Ondo States, Nigeria. Determinants of health and mortality in Africa (Edited by: Allan G Hill). Demographic and Health Survey Further Analysis Series. New York: The Population Council 1990, (10):1-45.

4. Awumbila, M., Manuh, T., Quartey, P., Tagoe, C. A. and Bosiakoh, T. A. (2009) Ghana Migration Country Paper: Trends, Issues, and Emerging Research Gaps, Legon, Ghana: Centre for Migration Studies, University of Ghana.

5. Babalola, S. \& Fatusi, A. (2009) Determinants of use of maternal health services in Nigeria-looking beyond individual and household factors. (9) 43

6. Babalola, S. \& Kincaid, D.L. (2009). New methods for estimating the impact of health communication programs. Commun Methods Meas 2009, 3:61-83.

7. Becker, S., Peters, D. H., Gray, R. H., Gultiano, C. \& Blake, R. E. (1993). The determinants of use of maternal and child health services in Metro Cebu, the Philippines. Health Transition Review, 3, 77-89.

8. Birkeland, N. M. (2003). Peace in Angola? Return Home for IDPs? Cathrine Brun and Nina Birkeland (eds): Researching Internal Displacement: state of the Art. Conference Proceedings, Trondheim Norway, $7-8$ February 2003. Acta-Geographica Series A, No.6, NTNU, Trondheim.

9. Birkmann, J., Buckle, P., Jaeger, J., Pelling, M., Setiadi, N., Garschagen, M., Fernando, N. \& Kropp, J. (2008). Extreme events and disasters; a window of opportunity for change? Analysis of organizational, institutional and political changes, formal and informal responses after mega-disasters, Nat Hazards DOI 10.1007/s11069-0089319-2

10. Bloom, S.S., Wypij, D., \& Gupta, M. (2001). Dimensions of women's autonomy and the influence on maternal health care utilization in a north Indian city. Demography 2001, 38:67-78.

11. Bosmans, M. et al. (2002). Reproductive and Sexual Rights of Refugee and Internally Displaced Women as Cornerstone of Respect for Human Rights. International Centre for Reproductive Health, Ghent University, Belgium, 2002)

12. Caravan, A. (2008). Review of global literature on maternal health interventions and outcomes related to provision of skilled birth attendance. Amsterdam: Royal Tropical Institute Development Policy and Practice

13. Casey, S. (2002). Assessment of Reproductive Health in Northern Sri Lanka. RHRC, December 2002). Cebu, the Philippines'. Studies in Family Planning, Vol. 29, No. 1 (Mar., 1998), pp. 69-78

14. Celik, Y. \& Hotchkiss, D.R. (2000). The socioeconomic determinants of maternal health care utilization in Turkey. Social Science and Medicine 50(12): 1797-1806.

15. Claeson, M. et al. (2001). Poverty reduction and the health sector: The health, nutrition and population network's chapter in the World Bank's poverty reduction strategy source book. Washington, DC, IBRD/World Bank

16. Cohen, M. \& Sebstad, J. (2003). Reducing Vulnerability: The Demand for Microinsurance. MicroSave-Africa, Kampala CRED, Annual Disaster Statistical review 2009, Centre for Research on the Epidemiology of Disasters (CRED), Brussels

17. Defra, (2005). Making Space for Water: Taking Forward a New Government Strategy for Flood and Coastal Erosion Risk Management in England. First Government Response to the Autumn 2004 Making Space for Water Consultation Exercise. London: Department for Environment, Food and Rural Affairs.

18. UNFPA (2000). Making Pregnancy and Childbirth Safer [fact sheet]. EC/UNFPA Initiative for Reproductive Health in Asia in cooperation with the German Foundation for World Population. Educational Attainment and Maternal Healthcare Utilization in Bangladesh: Evidence from the 2005 Bangladesh Household Income and Expenditure Survey'. Research Journal of Medical Sciences 4(1): 33-37, 2010

19. Elo, T. I. (1992). Utilization of maternal health-care services in Peru: the role of women's education. Health Transition Review, 2, 49-69.

20. Eludoyin, A.O., Akinbode, M.O. \& Okuku, E. (2007). Combating flood crisis with Geographical Information System: An Example from Akure Southwest Nigeria. International Symposium on New Direction in Urban water Management UNESCO, Paris 12-14 Epidemiology 1986, 16: 403-406.

21. Fatusi, A.O. \& Abioye-Kuteyi, E.A. (1998). Traditional birth attendants in Nigeria: what do we know about them? Defining the role of Traditional Birth Attendants in Nigeria. Proceedings of a National Workshop on the Roles of TBAs in Reproductive Health Lagos, United Nations Population Fund (UNFPA) 1998, 18-25. 
22. Fatusi, A.O. \& Ijadunola, K.T. (2003). National Study on Essential Obstetric Care Facilities in Nigeria Abuja, Federal Ministry of Health \& United Nations Population Fund (UNFPA) 2003.

23. Fatusi, A.O. \& Hindin, M.J. (2010). Adolescents and youth in developing countries: health and development issues in context. Journal of Adolescence 33(4): 499-508.

24. Ferris, E. (2012). "Internal Displacement in Africa: An Overview of Trends and Opportunities." Presentation at the Ethiopian Community Development Council Annual Conference "African Refugee and Immigrant Lives: Conflict, Consequences, and Contributions" 2-4 May 2012.

25. Fosu, G. B. (1994). Childhood morbidity and health services utilization: cross-national comparisons of userrelated factors from DHS data. Social Science and Medicine, 38, 1209-1220.

26. Gage, A.J. \& Calixte, M.G. (2006). Effects of the physical accessibility of maternal health services on their use in rural Haiti. Population Studies 60(3): 271-288.

27. Gardner, R. \& Blackburn, R. (1997). People who move: new reproductive health focus. Population Reports Series J, No. 45 (November 1997).

28. Gertler, P., Rahman, O., Feifer, C. \& Ashley, D. (1993). Determinants of pregnancy outcomes and targeting of maternal health services in Jamaica. Social Science Med 1993, 37:199-211.

29. Gill, S. (2004). Literature Review: Impacts of Climate Change on Urban Environments. Centre for Urban and Regional Ecology, University of Manchester.

30. Govender, V., McIntyre, D., \& Loewenson, R. (2008). 'Progress towards the Abuja target for government spending on health care in East and Southern Africa,' EQUINET Discussion Paper Series 57. EQUINET: Harare.

31. Haas, J.E., Kates, R.W., Bowden, M.J. (1977). Reconstruction following disaster, MIT Press, Cambridge.

32. Hazarika, I. (2011). Factors that determine the use of skilled care during delivery in India: implications for achievement of MDG-5 targets. Maternal and Child Health Journal 15(8): 1381-1388.

33. Heathwaite, A., Lane, S., Ward, N., Whatmore, S. \& Donaldson, A. (2005). Capacity Building Project on Bringing Together Natural and Social Science Perspectives on Understanding Diffuse Pollution. Final Report to project stakeholders and the RELU programme on project workshops January 2005.

34. Hill, K. and Haque, Y. (2007). 'Maternal Health and Care-Seeking Behavior in Bangladesh: Findings from a National Survey'. International Family Planning Perspectives, Vol. 33, No. 2 (Jun., 2007), pp. 75-82

35. Hynes, M. et al. (2002). Reproductive health indicators and outcomes among refugee and internally displaced persons in post-emergency phase camps. Journal of the American Medical Association, 2002288 (5): 595-603)

36. Internal Displacement Monitoring Centre. (2002). Internally Displaced People. A Global Survey. Second Edition. IDMC, Geneva and Earthscan, London.

37. Internal Displacement Monitoring Centre. (2004). Internal Displacement. Global Overview of Trends and Developments in 2003. IDMC, Geneva.

38. Kausar, F., Griffiths, P. \& Matthews, Z. (1999). Poverty and Maternal Healthcare Utilization in Maharashtra: Associated Influences on Infant Mortality and Morbidity

39. Kesterton, A.J, Cleland, J., Sloggett, A. \& Ronsmans, C. (2010). Institutional delivery in rural India: the relative importance of accessibility and economic status. BMC Pregnancy and Childbirth 10(30): 2-9.

40. KHRC, (2011) Gains and Gaps: A Status Report on Internally Displaced Persons in Kenya 2008-2010 Nairobi: KHRC

41. Knowles, J.C., Bales, S., Cuong, L.Q., Oanh, T.T. \& Luon, D.H. (2009). Health equity in Viet Nam: a situation analysis focused on maternal and child mortality. Ha Long: United Nations Children's Fund; 2009.

42. Krause, S., Jones, R. \& Purdin, S. (2000). Programmatic Responses to Refugees' Reproductive Health Needs. International Family Planning Perspectives, 2000, 26 (4): 181-187).

43. Krause, S., Morris, C. \& McGinn, T. (2003). Displaced and Desperate: Assessment of Reproductive Health for Colombia's Internally Displaced Persons. RHRC, February 2003

44. Ladan, M.T. (2003). "Overview of Reproductive Rights and Health" Journal of Economic, Social and Cultural Rights vol. 1 No. 7 Lagos, Socio Economic Rights Initiative (SERI) p. 20

45. Lederman, S. A. (2001). "Pregnancy weight gain and postpartum weight loss: Avoiding obesity while optimizing the growth and development of the fetus". Journal of the American Medical Women's Association, 56: $53-58$

46. Leslie, J. \& Gupta, G.R. (1989). Utilization of formal services for maternal nutrition and health care Washington DC, International Center for Research on Women 1989.

47. Magadi, M.A., Agwanda, A.O. \& Obare, F.O. (2007). A comparative analysis of the use of maternal health services between teenagers and older mothers in sub-Saharan Africa: evidence from Demographic and Health Surveys (DHS). Soc Sci Med 2007, 64:1311-1325. 
48. McCaw-Binns, A., Grenade, J. \& Ashley, D. (2007). Under-users of antenatal care: a comparison of nonattenders and late attenders for antenatal care with early attenders. Soc Sci Med 2007, 40:1003-1012.

49. McKinlay, J. B. (1972). Some approaches and problems in the study and use of services: an overview. Journal of Health and Social Behaviour, 13, 115-152. Medical Care Utilization in the United States'. The Milbank Quarterly, Vol. 83, No. 4, 2005 (pp. 1-28)

50. Mekonnen, Y. \& Mekonnen, A. (2003). Factors influencing the use of maternal healthcare services in Ethiopia. Journal on Health Popul Nutr 2003, 21:374-382.

51. Meriwether, B., Jones, R. \& McGinn, T. (2001). Assessment of Reproductive Health for IDPs, Angola. New York: RHRC, February 2001.

52. Merlin, (2008). Case Study of Maternal mortality: Sudan All Parliamentary Group on Population Development and Reproductive Health

53. Mpembeni, R.N., Killewo, J.Z. \& Leshabari, M.T. (2007). Pattern of maternal health services and determinants of skilled care during delivery in Southern Tanzania: implication for achievement of MDG-5 targets, BMC preg and childbirth, 2007; 7: 1-7

54. Mrisho, M., Obrist, B., Schellenberg, J.A., Haws, R.A., Mushi, A.K. (2009). 'The use of antenatal and postnatal care: perspectives and experiences of women and healthcare providers in rural Southern Tanzania'. BMC Pregnancy and Childbirth 2009, 9:10

55. Mushi, D. and Mwakipa, H. (2007). 'Use pattern of maternal health services and determinants of skilled care during delivery in Southern Tanzania: implications for achievement of MDG-5 targets'. BMC Pregnancy and Childbirth 2007, 7:29

56. Nai-Adjei, M. (2008). Factors Contributing to Low Utilization of Skilled Delivery in Ahafo Ano, South District, Ashanti Region, Ghana. Thesis submitted to the School of Graduate Studies.

57. National Population Commission (NPC) [Nigeria] and ICF Macro (2009). Nigeria Demographic and Health Survey 2008. Abuja, Nigeria: National Population Commission and ICF Macro

58. National Population Commission [Nigeria] and ORC Macro (2003). Nigeria Demographic and Health Survey 2003 Calverton, Maryland: NPC and ORC Macro 2004.

59. Ngari, M. (2011). "Rising Health costs take toll on families": During launching of Kenya National Health Accounts 2009/10 Report, 6th December, 2011, Nairobi, in Daily Nation

60. Obermeyer, C.M. \& Potter, J.E. (1991). Maternal health care utilization in Jordan: a study of patterns and determinants. Studies Family Planning 1991, 22:177-187.

61. Odimegwu, C. \& Ononokpono, D. (2014). Determinants of maternal health care utilization in Nigeria: a multilevel approach: Pan African medical journal, 2014; 17(supp 1): Maternal Morbidity and Mortality in Nigeria. The use of maternal health services between teenagers and older mothers in sub-saharan Africa: Evidence from demographic health surveys'. Social Science \& Medicine 64 (2007) 1311-1325

62. Okafor, C.B. (1991). Availability and use of services for maternal and child health care in rural Nigeria. International Journal on Gynaecol Obstet 1991, 34:331-46.

63. Onah, H.E., Ikeako, L.C. \& Iloabachie, G.C. (2006). Factors associated with the use of maternity services in Enugu, south eastern Nigeria. Soc Sci Med 2006, 63:1870-1878.

64. Orubuloye, I.O. \& Caldwell, J.C. (1975). The impact of public health services on mortality: a study of mortality differentials in a rural area of Nigeria. Population Studies 1975, 29:259-272.

65. Osubor, K.M., Fatusi, A.O., and Chiwuzie, J.C. (2006). 'Maternal HealthSeeking Behaviour and Associated Factors in a Rural Nigerian Community'. Maternal and Child Health Journal, Vol. 10, No. 2, March 2006

66. Ram, F. \& Singh, A. (2006). Is antenatal care effective in improving maternal health in rural Uttar Pradesh: evidence from a district level household survey. Journal of Biosocial Science 38(4): 433-448.

67. Reynolds, H.W., Wong, E.L. \& Tucker, H. (2006). Adolescents use of maternal and child health services in developing countries. International Family Planning Perspectives 32(1): 6-16.

68. Ronsmans, C., Chowdhury, M.E., Koblinsky, M. \& Ahmed, A. (2010). Care seeking at time of childbirth, and maternal and perinatal mortality in Matlab, Bangladesh. Bulletin of the World Health Organisation 88(4): 289296.

69. Saikia, N. \& Singh, A. (2009). Does type of household affect maternal health? evidence from India. Journal of Biosocial Science 41(3): 329-353.

70. Singh, L., Rai, R.K. \& Singh, P.K. (2012). Assessing the utilization of maternal and child health care among married adolescent women: evidence from India. Journal of Biosocial Science 44(1): 1-26. 
71. Smith, B.W. (1996). Coping as a predictor of outcomes following the 1993 Midwest flood. Journal of Social Behavior \& Personality:11(2) June, 225-239. Social Science \& Medicine 59 (2004) 1127-1146

72. Stephenson R, Tsui AO (2002) Contextual influences on reproductive health service use in Uttar Pradesh, India. Studies in Family Planning 33(4): 309-320.

73. Stewart, K. \& Sommerfelt, A.E. (1991). Utilization of maternity care services: A comparative study using DHS data. Proceedings of the Demographic and Health Surveys World Conference. Washington, DC 1991, III:16451668.

74. Titaley, C.R., Hunter, C.L., Heywood, P. and Dibley, M.J. (2010). 'Why do some women still prefer traditional birth attendants and home delivery: a qualitative study on delivery care services in West Java Province, Indonesia'. BMC Pregnancy and Childbirth 2010, 10:43

75. Treffers, P.E., Olukoya, O.O., Ferguson, B.J. and Liljestrand, J. (2001). 'Care for adolescent pregnancy and childbirth'. International Journal of Gynaecol \& Obstet 2001 Nov; 75(2): 111-21

76. Tuddenham, S.A., Rahman, M.H., Singh, S., Barman, D. \& Kanjilal, B. (2010). Care seeking for postpartum morbidities in Murshidabad, rural India. International Journal of Gynecology and Obstetrics 109(3): 245-254.

77. United Nations High Commission for Refugees. (1999). Reproductive Health in Refugee Situations. An InterAgency Field Manual. Geneva: UNHCR (1999).

78. van Eijk, A.M., Bles, H.M., Odhiambo, F., Ayisi, J.G., Blokland, I.E., Rosen, D.H., Adazu, K., Slutsker, L. \& Lindblade, K.A. (2006). Use of antenatal services and delivery care among women in rural western Kenya: a community-based survey. Reproductive Health 2006, 3:2.

79. Verma, K., Thomas, A., Sharma, A., Dhar, A. \& Bhambri, V. (2001). Maternal mortality in rural India: a hospital based 10-year retrospective analysis. Journal of Obstetrics and Gynaecology Research 27(4): 183-187.

80. Waage, J., Banerji, R., Campbell, O., Chirwa, E., Collender, G., \& Dieltiens V. (2010). The Millennium Development Goals: a cross-sectoral analysis and principles for goal setting after 2015. Lancet 2010; 376: 991 1023

81. Wagle, R., Sabroe, S. \& Nielsen, B.B. (2004). Socio-economic and physical distance to the maternity hospital as predictors for place of delivery: an observation study from Nepal. BMC Pregnancy and Childbirth 4(1): 8 20.

82. Wall, L.L. (1998). Dead Mothers and injured wives: the social context of maternal morbidity and mortality among the Hausa of Northern Nigeria. Studies Family Planning 1998, 29:341-359.

83. Wong, E. L., Popkin, B. M., Gullkey, D. K. and Akin, J. S. (1987). Accessibility, quality of care and prenatal care use in the Philippines. Social Science and Medicine, 24, 927-944.

84. World Bank. (2010) "Trends in Maternal Mortality: 1990 to 2008. Geneva, Switzerland.

85. World Health Organisation. (1998). Postpartum care of the mother and newborn: A practical guide. Maternal and Newborn Health/Safe Motherhood Unit, Division of Reproductive Health (Technical Support), Geneva, Switzerland.

86. World Health Organisation. (2005). Provision of effective antenatal care: Integrated Management of Pregnancy and Child Birth (IMPAC). Standards for Maternal and Neonatal care (1.6), Department of Making Pregnancy Safer, Geneva, Switzerland.

87. World Health Organisation. (2007). Maternal mortality in 2005: estimates developed by WHO, UNICEF, UNFPA, and the World Bank Geneva, WHO 2007.

88. Wright, J.D., Rossi, P.H. Wright, S.R. \& Weber-Burdin, E. (1979). After the clean-up: long range effects of natural disasters. Sage, Beverly Hills.

89. Yadav, K., Jarhyan, P., Gupta, V. \& Pandav, C.S. (2009). Revitalising rural health care delivery: can rural health practitioners be the answer. Indian Journal of Community Medicine 34(1): 3-5. 